\title{
Developmental venous anomaly associated with cortical dysplasia
}

\author{
Darshana D. Rasalkar • Bhawan K. Paunipagar
}

Received: 15 January 2010 /Revised: 9 February 2010 /Accepted: 15 March 2010 / Published online: 29 April 2010

(C) Springer-Verlag 2010

A 15-year-old boy presented with intermittent generalized seizures. An electroencephalogram showed spike and wave complexes with sporadic slowing in the right frontal regions. Brain CT revealed an ill-defined hyperdensity and a few calcified foci in the right frontal cortex and subcortical white matter. Cranial MRI showed corresponding FLAIR hyperintensity with prominent flow void at its lateral aspect (Fig. 1). Differential diagnoses included cortical dysplasia, vascular malformation and oligodendroglioma. Angiography revealed a normal arterial phase, but enlarged medullary and cortical venous channels were noted draining into the superior sagittal sinus (Fig. 2), which suggested the

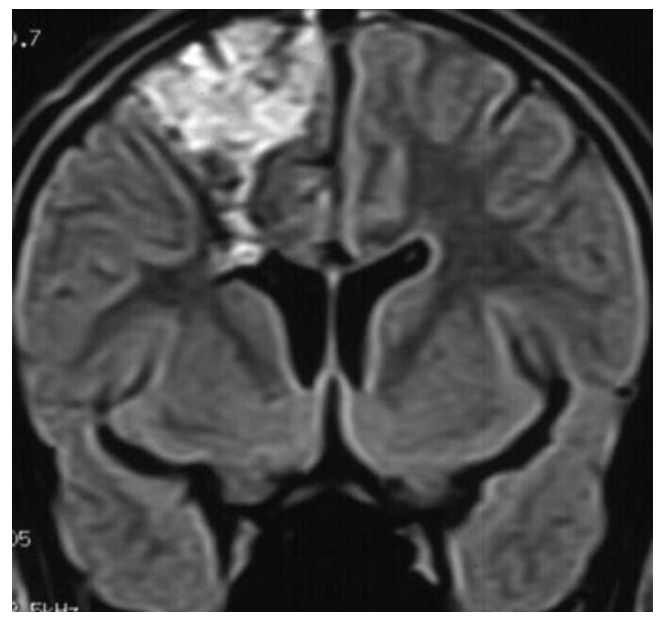

Fig. 1 Coronal FLAIR

D. D. Rasalkar $(\bowtie) \cdot$ B. K. Paunipagar

Department of Diagnostic Radiology and Organ Imaging, Prince of Wales Hospital, The Chinese University of Hong Kong, Ngan Shing Street, Shatin N.T.,

Hong Kong, China

e-mail: darshana@cuhk.edu.hk

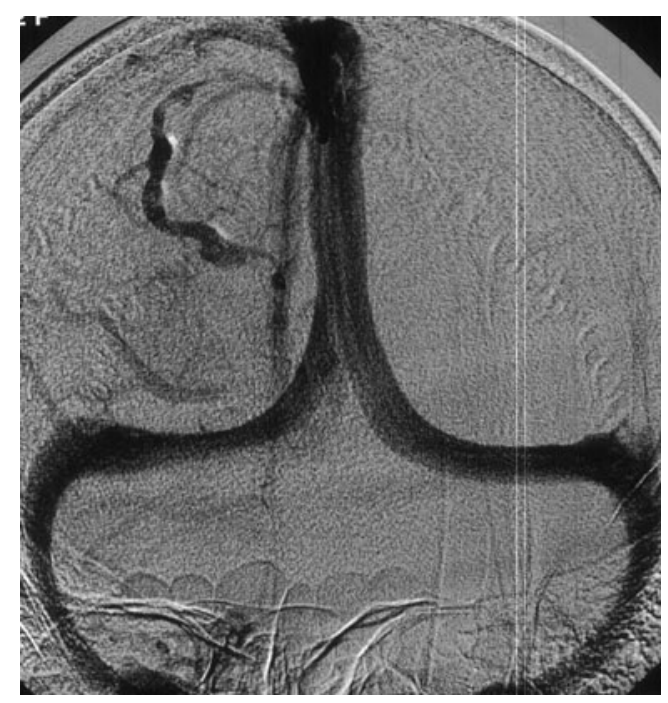

Fig. 2 Angiogram, venous phase

diagnosis of cortical dysplasia with developmental venous anomaly.

Cortical dysplasia is a neuronal migration anomaly. There are several categories of neuronal migration anomalies depending on the timing and severity of the injury and their appearances [1]. Abnormal or prominent venous drainage has been described in association with cortical dysplasia [2].

\section{References}

1. Barkovich AJ (1995) Congenital malformations of the brain and skull. In: Pediatric neuroimaging (2nd edn) Raven Press, NY, pp 177-275

2. Barkovich AJ (1988) Abnormal vascular drainage in anomalies of neuronal migration. AJNR 9:939-942 